\title{
Novel bio-based epoxy-polyurethane materials from modified vegetable oils - synthesis and characterization
}

\author{
A. Sienkiewicz, P. Czub* \\ Department of Chemistry and Technology of Polymers, Faculty of Chemical Engineering and Technology, Cracow \\ University of Technology, Warszawska Str. 24, Kraków, Poland
}

Received 19 October 2016; accepted in revised form 6 December 2016

\begin{abstract}
Presented research shows the results of a study on the mechanical properties of materials obtained in the course of innovatory application of epoxidized vegetable oil in the synthesis of new bio-based epoxy resins, crosslinked with curing agents which are not typical for epoxy materials. The product was obtained via modern and pro-ecological modification of a well-known synthesis method of epoxies, namely the epoxy fusion process, then it was crosslinked using polyisocyanates of different structure: toluene-2,4-diisocyanate (TDI), hexamethylene diisocyanate (HDI) and 4,4'-methylene diphenyl diisocyanate (MDI). The obtained epoxy-polyurethane materials are characterized by various mechanical properties, which depend on the type of chosen isocyanate. Compositions based on HDI exhibit better mechanical characteristics than elastic polyurethane materials based on hydroxylated soybean oil. Materials cured with aromatic isocyanates MDI and TDI are characterized by higher mechanical resistance comparable with cast polyurethane based on petrochemical resources. Epoxy fusion product cured with toluene-2,4-diisocyanate in a presence of Dabco T9 appears to have the best mechanical properties among all tested compositions.
\end{abstract}

Keywords: biopolymers, soybean oil, epoxy resin, epoxy fusion process, isocyanates

\section{Introduction}

Epoxy resins are one of the most common thermosets which are widely used as adhesives in various applications: in the aerospace industry, construction composite materials, surface coatings [1], materials in machine building including automotive and ship industries, packaging materials for electronic devices, as well as in medicine or home fields [2-4]. Among the most valuable properties of epoxies, good adhesion to various substrates, high modulus, high temperature performance, low shrinkage and good corrosion resistance $[5,6]$ are only a few to mention. On the other hand these polymer materials are characterized by high rigidity and brittleness, somewhat limiting their scope of applicability. It is necessary to mention here, that properties of the crosslinked products depend both on the chemical composition of the mixture, as well as on the crosslinking conditions. Knowledge regarding the curing kinetics and thermal stability of cured material to achieve the desired characteristics is necessary. Epoxy resins can be cured with different kinds of curing agents. Typical chemical compounds used for this purpose - in the presence or absence of catalysts - are aromatic or aliphatic amines and multifunctional acids or anhydrides [7]. Recently, due to the wide application of epoxy resins, research efforts to improve their physical and mechanical properties have been very intensive, focusing on the modifications towards receiving tougher and thermally more resistant material. Moreover, application of renewable resources in their synthesis and modification is also of great interest, due to the growing ecological issues as well as economical and societal advantages $[8,9]$. Vegetable oils, which are biodegradable, renewable,

$\overline{{ }^{*} \text { Corresponding author, e-mail: pczub@pk.edu.pl }}$

(C) BME-PT 
non-toxic, environmentally benign and easily modified $[10,11]$ have already found applications in the technology of epoxies as: additives, flexibilizers [12], and diluents [13], decreasing viscosity of epoxy resins or bio-alternatives for raw petrochemical materials in the process of their synthesis $[14,15]$. In a respect of functionality of vegetable oils, defined as content of unsaturated bonds and in the same time content of functional groups, which might be introduced in to the molecule, epoxidized derivatives of natural oils can be formally classified as epoxy resins. Furthermore, they can be successfully applied in the epoxy fusion process with bisfenol A, leading to the synthesis of interesting novel bio-based polymer materials with the diverse contents of epoxy and hydroxyl groups.

One of the most typical synthesis method of the high molecular weight (1500-10000 g/mol) epoxy resins is the epoxy fusion process involving low- and average molecular weight epoxies and bisphenols [7]. This innovatory synthesis has numerous advantages, such as: simplicity and opportunity of obtaining product with tailored properties and molecular weight, much higher than via conventional solvent method, and moreover, without the necessity of application of harmful for environment solvents, strong acids and alkali, what is important in the era of environmental awareness [16]. Additionally, this process allows introducing vegetable oils in the synthesis process of epoxy resins, resulting in obtaining a pro-ecological product with better application characteristics (lower viscosity $[13,17]$ and higher resilience) than via the conventional method which relies on the use of petrochemical raw materials. There are two main paths of application of modified vegetable oils in obtaining high-molecular weight epoxy products in the epoxy fusion process, by using either an epoxidized or hydroxyl natural oil. Our research group has already performed experiments on possibility of application of the hydroxyl derivative of soybean oil (SDEG) in epoxy fusion process with bisphenol A-based lowmolecular-weight epoxy resin EPR 162 [18].

On the basis of type of functional groups, the innovational epoxies may be cured with various curing agents, typical for epoxy resins [19]. However, we have conducted experiments on the application of isocyanates, typical for polyurethane technology, and as a result we obtained hybrid polymer materials with interesting mechanical properties [20]. Products of the epoxy fusion process of epoxidized soybean oil and bisphenol A contain a relatively large amount of free hydroxyl groups (comparable to that of polyols based on vegetable oils) [21, 22], which may be susceptible to the reaction with isocyanates.

The aim of this paper is to describe the synthesis of new bio-based epoxy resins and to determinate the mechanical characteristics of the obtained materials cured with isocyanates, as well as to define the influence of the used catalysts (Dabco T9 or Dabco 33$\mathrm{LV}$ ) on the crosslinking process and the properties of obtained materials.

\section{Material and methods}

\subsection{Materials}

In the performed epoxy fusion process epoxidized soybean oil (ESBO, Ergoplast EG, Boryszew, EV = $0.363 \mathrm{~mol} / 100 \mathrm{~g}$; with an average 3.52 epoxide groups and 0.03 hydroxyl groups per 1 oil molecule), bisphenol A (BPA, GE Cartagenie, 99.93\%) and $\mathrm{LiCl}$ (Merck, pure) were used.

Crosslinking of synthesized epoxy fusion product was carried out with the following reagents.

\section{One of curing agents}

- Desmodur L75 (Bayer Material Science, Germany), $75 \mathrm{wt} \%$ solution of aromatic isocyanate toluene-2,4-diisocyanate (TDI) in ethyl acetate, containing $13.3 \mathrm{wt} \%$ of free $-\mathrm{NCO}$ groups and viscosity of $1600 \mathrm{mPa} \cdot \mathrm{s}\left(23^{\circ} \mathrm{C}\right)$ and density of $1.17 \mathrm{~g} / \mathrm{cm}^{3}$.

- Desmodur N75 (Bayer Material Science, Germany), $75 \mathrm{wt} \%$ solution of aliphatic isocyanate hexamethylene diisocyanate (HDI) basis in 1-methoxy-2-propyl acetate and xylene (1:1), containing $16.5 \mathrm{wt} \%$ of free $-\mathrm{NCO}$ groups and viscosity of $250 \mathrm{mPa} \cdot \mathrm{s}\left(23^{\circ} \mathrm{C}\right)$ and density of $1.07 \mathrm{~g} / \mathrm{cm}^{3}$.

- Desmodur VL (Bayer Material Science, Niemcy), aromatic polyisocyanate based on 4,4'-methylene diphenyl diisocyanate (MDI) and containing $31.5 \mathrm{wt} \%$ of free $-\mathrm{NCO}$ groups and viscosity of $90 \mathrm{mPa} \cdot \mathrm{s}\left(25^{\circ} \mathrm{C}\right)$ and density of $1.24 \mathrm{~g} / \mathrm{cm}^{3}$.

\section{Selected catalyst}

- Dabco T9 (Air Products and Chemicals, Inc., USA) - tin bis(2-ethylhexanoate ) - $97 \mathrm{wt} \%$ of stannous octoate and $3 \mathrm{wt} \%$ of 2-ethylhexanoic acid.

- Dabco 33-LV (Air Products and Chemicals, Inc., USA) - a mixture of $33 \mathrm{wt} \%$ of triethylene diamine and $67 \mathrm{wt} \%$ of dipropylene glycol.

Deaerator on silicone basis - BYK A530 


\subsection{Fusion process}

Epoxidized soybean oil (ESBO), bisphenol A and $\mathrm{LiCl}$ (in amount of $0.002 \mathrm{~mol}$ per $1 \mathrm{~mol}$ of bisphenol A) were used in the epoxy fusion reactions. Process was carried out in nitrogen atmosphere. Amounts of reagents were established with the respect to the required properties of the final product $(\mathrm{EV} \approx 0.100 \mathrm{~mol} / 100 \mathrm{~g})[22,23]$. In the first step the epoxidized soybean oil was heated to $110^{\circ} \mathrm{C}$ and an appropriate amount of the BPA was added. The reaction mixture was homogenized, followed by adding $\mathrm{LiCl}$ and rising the temperature to the desired $160^{\circ} \mathrm{C}$. Epoxy fusion process was conducted in $160^{\circ} \mathrm{C}$, over a period of $18 \mathrm{~h}$ (the duration of the process was established experimentally, by monitoring the epoxy value of reacting mixture) in a presence of $\mathrm{LiCl}$ (0.002 mol per $1 \mathrm{~mol}$ of bisphenol A) [24].

\subsection{Composition's crosslinking and samples preparation for mechanical testing}

Crosslinking of epoxy fusion product was conducted with the use of selected isocyanate - Desmodur VL, N75 or L75 in a stoichiometric amount with respect to hydroxyl groups in hardened material. Each composition contained $1 \mathrm{wt} \%$ of BYK A530 deaerator. Additionally, the influence of catalysts: Dabco T9 and Dabco 33-LV on the crosslinking process and mechanical properties of the cured compositions was examined. After intensive mixing, the prepared compositions were poured into the forms made of polytetrafluoroethylene (PTFE) and left for hardening at room temperature for 24 hours. Then the samples were removed from forms and annealed in $80^{\circ} \mathrm{C}$ for another 24 hours.

\subsection{Measurement methods}

\subsubsection{Spectroscopic measurements}

The transmittance FT-IR spectroscopy analysis was carried out using the FT-IR Perkin-Elmer system spectrophotometer (SPECTRUM 65 FT-IR, Perkin Elmer, UK). The measurements of liquid films were performed between $\mathrm{KBr}$ cell windows. A drop of oil samples was placed between two $\mathrm{KBr}$ windows, then spread evenly on their surface. Subsequently, oil samples spectra were registered in the range of 4000 $400 \mathrm{~cm}^{-1}$, at a temperature of $20-22^{\circ} \mathrm{C}$ and with the resolution of $4 \mathrm{~cm}^{-1}$. Samples of the obtained compositions were analyzed using the same spectrometer equipped with ZnSe crystal attenuated total reflectance unit (ATR). Spectra were recorded with resolution of $4 \mathrm{~cm}^{-1}$ from 4000 to $400 \mathrm{~cm}^{-1}$ with an average of 32 scans. The collected spectra present the dependence of transmittance $T$ [\%] and wave number $v\left[\mathrm{~cm}^{-1}\right]$.

\subsubsection{Gel permeation chromatography}

The number-average molecular weight $\left(\bar{M}_{\mathrm{n}}\right)$, weightaverage molecular weight $\left(\bar{M}_{\mathrm{w}}\right)$, and polydispersity (PDI) of the obtained products were determined by Knauer gel-permeation chromatography with two PL-gel columns $(300 \times 7.5 \mathrm{~mm})$ with grain size $3 \mu \mathrm{m}$ and MIXED-E pores and a refractive index detector. The equipment was calibrated using standard polystyrene samples in the molecular weight range of 410 to 20500 [g/mol]. The analyses were performed at $25^{\circ} \mathrm{C}$ and tetrahydrofuran dried over metallic sodium, distilled and stabilized with BHT (2,6-bis(1,1dimethylethyl)-4-methylphenol), was used as an eluent (with eluent flow $0.8 \mathrm{~mL} / \mathrm{min}$ ).

\subsubsection{Rheological characteristics of products}

A HAAKE MARS III rheometer (Thermo Scientific, Karlsruhe, Germany) was used in this experiment to measure the viscosity of the soybean oil, epoxidized and fusion products under shear rates of $30 \mathrm{~s}^{-1}$ at 25 and $50^{\circ} \mathrm{C}$. The equipment was connected with a computer to collect and store data by using rheology software - HAAKE RheoWin 3.

\subsubsection{Scanning electron microscopy}

Backscattered electron images of the impact fracture surface of the compositions were recorded by a JEOL JSM-6010LA (Tokyo, Japan) scanning electron microscope at accelerating voltages of $5 \mathrm{kV}$ and coating all samples with gold.

\subsubsection{Thermogravimetric analysis}

The thermal stability of selected compositions was determined using the Netzsch TG 209 apparatus by heating samples (weighing about $5 \mathrm{mg}$ ) in the temperature range of $25-600{ }^{\circ} \mathrm{C}$ in the synthetic air atmosphere $(15 \mathrm{~mL} / \mathrm{min})$.

\subsubsection{Epoxy and hydroxyl values}

Epoxy and hydroxyl values were evaluated by titration methods. Content of epoxy groups (epoxy value, EV) in the investigated products was evaluated according to $\mathrm{PN}-87 / \mathrm{C}-89085 / 13$ standard: the samples were dissolved in $\mathrm{HCl} / 1$,4-dioxane solution $(1.9 \mathrm{~mol} / \mathrm{L})$ and titrated by $\mathrm{NaOH} /$ methanol $(0.2 \mathrm{~mol} / \mathrm{L})$ in a pres- 
ence of cresol red as indicator to the visual change of tint to purple (from light pink through yellow to $\mathrm{red} /$ purple). This method involves the quantitative reaction of hydrogen chloride with epoxy groups in an environment of 1,4-dioxane at room temperature and then the titration of excess hydrogen chloride with standard alcoholic solution of sodium hydroxide. The indicator, cresol red, changes its color depending on the $\mathrm{pH}(\mathrm{pH}=7.2-$ yellow to $8.8-$ red $)$ of the solution. In order to define the hydroxyl value (HV), samples of soybean oil, its epoxidized and fusion products were dissolved in the solution of catalyst [4(dimethylamine)pyridine in DMF $-0.1 \mathrm{~mol} / \mathrm{L}$ ] and acetic anhydride in $\mathrm{DMF}(2.4 \mathrm{~mol} / \mathrm{L})$, respectively. This was followed by intensive stirring for $15 \mathrm{~min}$ utes and titration with $\mathrm{KOH}$ aqueous solution $(1 \mathrm{~mol} / \mathrm{L})$ in presence of thymolphthalein until the tint changed from colorless to blue. The method of hydroxyl value determination involves acetylation of hydroxyl groups with acetic anhydride, then with water - the decomposition of the excess of acetic anhydride to acetic acid and finally titration by the potassium hydroxide solution. The indicator, thymolphthalein, changes its color depending on the $\mathrm{pH}$ of the solution ( $\mathrm{pH}<9.3$ - colorless, $\mathrm{pH}>10.5$ - blue).

\subsubsection{Mechanical properties}

The mechanical properties of the prepared composition were tested on samples in the forms of paddles, beams and rollers. The tensile strength, elongation at break, modulus elasticity, flexural strength, elasticity flexural modulus, deflection, compressive strength and compression set were tested on the Zwick 1445 apparatus. The tensile strength, elongation at break, modulus elasticity were determined according to PNEN ISO 527-1:2012 standard on samples in form of paddles (type B) [section measurement with dimensions: $4 \times 10$ (at cross - section) and $50 \mathrm{~mm}$ (length)] and using the Zwick apparatus equipped with an extensometer. Measurements were conducted at $5 \mathrm{~mm} / \mathrm{min}$ testing speed. Flexural strength, elasticity flexural modulus, deflection were tested according to PN-EN ISO 178:2011 standard: samples were in a form of cuboids' beams with the cross-section dimensions of $4 \times 10 \mathrm{~mm}, 64 \mathrm{~mm}$ spacing between supports and testing speed of $10 \mathrm{~mm} / \mathrm{min}$. Compressive strength and compression set were tested according to PN-EN ISO 604:2006 standard: samples were in a form of rollers with $10 \mathrm{~mm}$ diameter and $25 \mathrm{~mm}$ height with the testing speed of $0.8 \mathrm{~mm} / \mathrm{min}$.
Hardness in Shore's A scale was tested according to PN-EN ISO 868:2005 standard with the use of the InSize apparatus.

Impact strength without notched by the Charpy's method PN-EN ISO 179-2:2001 was tested on the ZORN PSW 4J Digital apparatus, using cuboids' beams with the cross-section dimensions $4 \times 10 \mathrm{~mm}$.

\section{Results and discussion}

Results presented below are a part of the research on the first path of the synthesis of novel epoxy materials involving the application of epoxidized vegetable oil into the process of obtaining the epoxy resins. In the performed research commercially manufactured soybean oil was used. The amount of BPA was calculated basing on the change of functional groups quantity in substrates and products of the reaction, and under an assumption that the obtained product should have $\mathrm{EV} \approx 0.100 \mathrm{~mol} / 100 \mathrm{~g}$ [21-23]. The chosen catalyst, $\mathrm{LiCl}$, favors the reactions of phenol groups of bisphenol A with epoxy groups over the possible reaction of secondary hydroxyl groups (obtained by oxirane ring opening) with epoxy groups. Moreover, it inhibits branching reaction and thus prevents gelling of the reacting mixture (Figure 1).

The presented epoxy fusion process (Figure 1) involves reagents with different functionality, 2 for bisphenol A and on average more than 3 for epoxidized soybean oil. Typically in the polyaddition or polycondensation process, functionality of one of the reagents greater than 2 leads to crosslinked products. However, as it had been proven, skillful conduction of the epoxy fusion process in a presence of $\mathrm{LiCl}$ catalyst leads to a product with designed characteristics, in a form of liquid with high density and without gelling of the mixture. The structure of epoxy product was characterized by FT-IR (Table 1), GPC (Figure 2) and functional group determination (epoxy and hydroxyl groups content) (Table 2). After $18 \mathrm{~h}$ of conducting the process, it was possible to obtain a decrease of epoxy groups content on the level of $0.118 \mathrm{~mol} / 100 \mathrm{~g}$, while the hydroxyl value was $144 \mathrm{mg} \mathrm{KOH} / \mathrm{g}$.

In the FT-IR spectrum of the of epoxidized soybean oil, signals with little intensity, characteristic for epoxy group are visible at $v=1240$ and $v=832 \mathrm{~cm}^{-1}$ (Table 1 and Figure 4). The other peaks observed from the FT-IR spectrum are at: $725 \mathrm{~cm}^{-1}$ (methylene in-phase rocking), $1240 \mathrm{~cm}^{-1}$ (ester antisymmetric stretch), $1380 \mathrm{~cm}^{-1}$ (methyl symmetric deformation), 

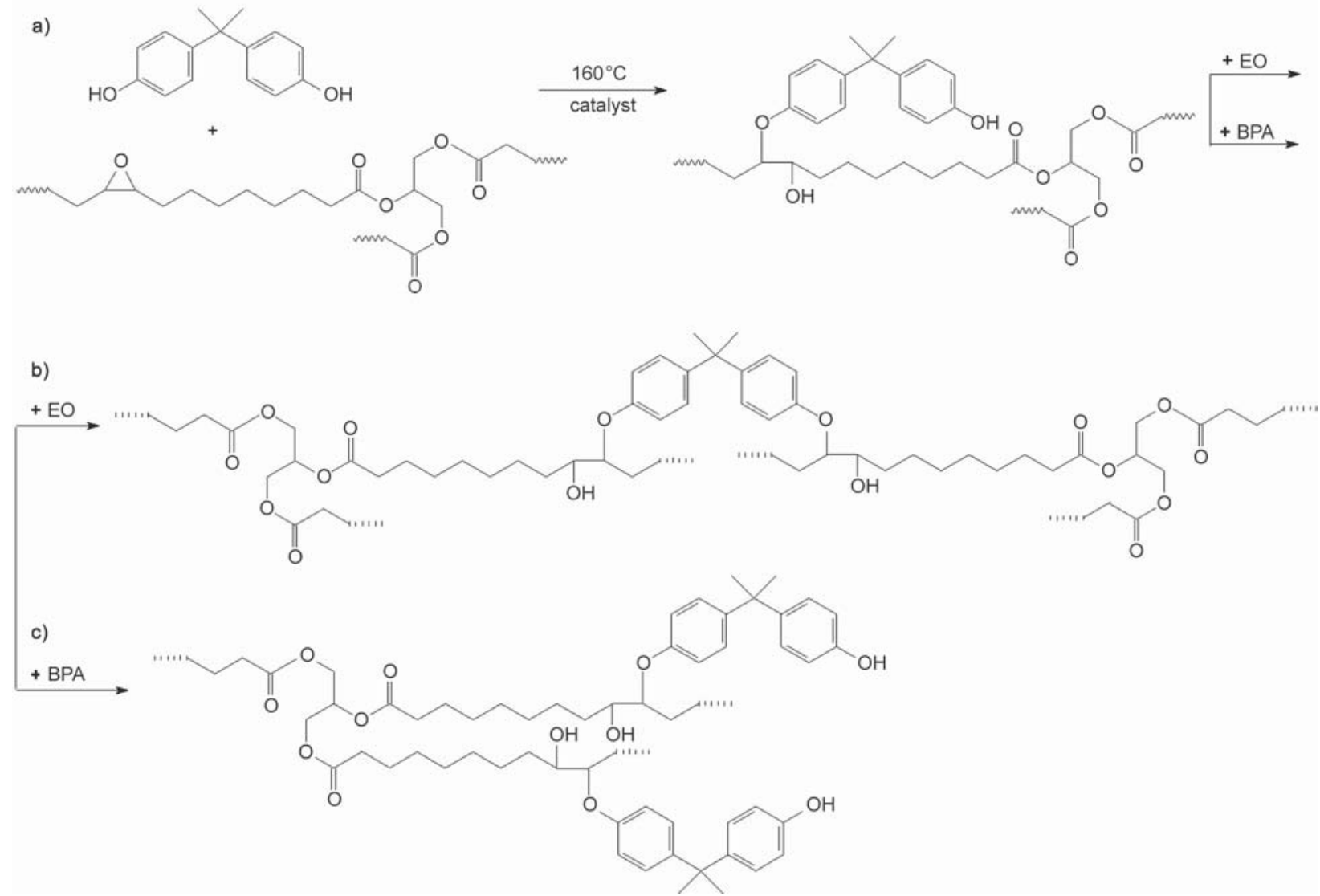

Figure 1. The initial stage of polyaddition - reactions between molecules of epoxidized oil (EO) and bisphenol (a), subsequent reactions leading to linear oligomers formation (b), second of possible subsequent reactions (involving free epoxy groups in the oil molecule), followed by formation of branched oligomers (c)

$1465 \mathrm{~cm}^{-1}$ (methyl antisymmetric deformation) and $1744 \mathrm{~cm}^{-1}$ (esters, aliphatic $\mathrm{C}=\mathrm{O}$ stretch). Spectrum of ESBO_BPA confirms that the reaction between epoxidized soybean oil and bisphenol A took place, and the obtained product consists both epoxy and free hydroxyl groups. FT-IR spectra of ESBO_BPA still contain bands from oxirane groups, however, their intensity decreased and they are visible at

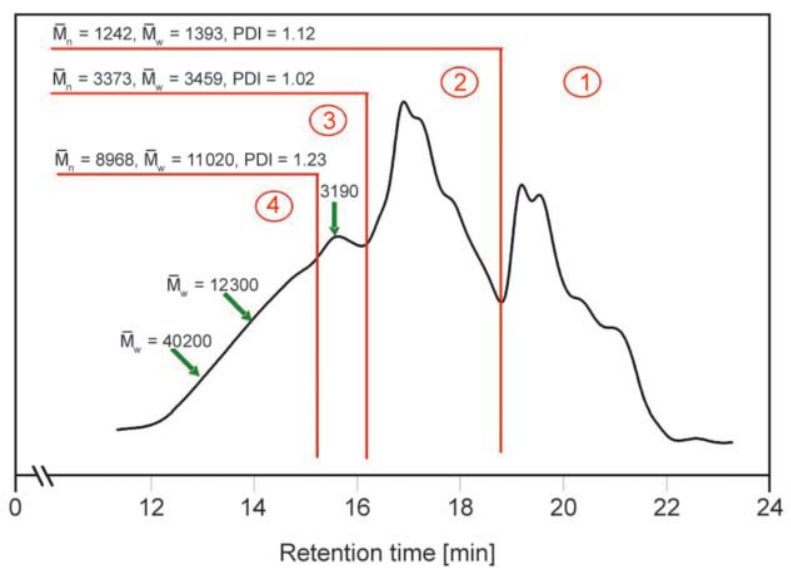

Figure 2. The chromatogram of the product of the epoxy fusion process of epoxidized soybean oil and bisphenol A $v=1238 \mathrm{~cm}^{-1}$. The band at $v=832 \mathrm{~cm}^{-1}$, due to its very small intensity is not visible and might be overlapping with the signal from isopropyl group $\left(v=842 \mathrm{~cm}^{-1}\right)$ from bisphenol A, which has a relatively high intensity. Additionally, wide signal at $v=3412 \mathrm{~cm}^{-1}$ is visible, which can be assigned to hydroxyl groups. Comparison of FT-IR spectra of ESBO and ESBO_BPA, shows that a decrease of the intensity of the signal from epoxy groups is related to a decrease of their contents in the epoxy fusion product, which proves that the reaction between epoxidized soybean oil and bisphenol A took place. The results of GPC analysis (Figure 2) show that the product of epoxy fusion process is a mixture of oligomers of various sizes. Dominate rather small macromolecules created by the attachment of one molecule of bisphenol A to the molecule of epoxidized triglyceride (Figure 1a and Figure 2, section 2) and slightly larger, as a result of further attachment of bisphenol A molecules to the same triglyceride molecule (due to the presence of free epoxy groups - epoxidized soybean oil contains 3.4 epoxide groups per one molecule) (Figure 1c), and then connection with another 
Table 1. FT-IR analysis of epoxidized soybean oil and epoxy fusion product of epoxidized soybean oil and bisphenol A

\begin{tabular}{|c|c|c|c|}
\hline Band & $\begin{array}{l}\text { Frequency } \\
{\left[\mathrm{cm}^{-1}\right]}\end{array}$ & & Associated band \\
\hline \multirow{11}{*}{$\begin{array}{l}0 \\
\text { ڤ్ } \\
\text { II }\end{array}$} & 2930 & $-\mathrm{CH}_{2}$ & asymmetric stretching \\
\hline & 2856 & $-\mathrm{CH}_{2}$ & symmetric stretching \\
\hline & 1744 & $-\mathrm{C}=\mathrm{O}$ & stretching \\
\hline & 2930 & $-\mathrm{CH}_{2}$ & asymmetric stretching \\
\hline & 2856 & $-\mathrm{CH}_{2}$ & symmetric stretching \\
\hline & 1744 & $-\mathrm{C}=\mathrm{O}$ & stretching \\
\hline & 1465 & $\begin{array}{l}-\mathrm{C}=\mathrm{O} \\
-\mathrm{CH}_{2}\end{array}$ & $\begin{array}{l}\text { stretching } \\
\text { scissor deformational }\end{array}$ \\
\hline & 1380 & $\begin{array}{l}-\mathrm{C}=\mathrm{C} \\
-\mathrm{CH}_{3}\end{array}$ & symmetric deformational \\
\hline & 1240 & $\begin{array}{l}-\mathrm{C}-\mathrm{O}-\mathrm{C}- \\
-\mathrm{CH}_{2}\end{array}$ & $\begin{array}{l}\text { epoxy group stretching } \\
\text { stretching }\end{array}$ \\
\hline & 832 & $-\mathrm{C}-\mathrm{O}-\mathrm{C}-$ & epoxy group stretching \\
\hline & 725 & $-\mathrm{CH}_{2}$ & oscillating \\
\hline \multirow{12}{*}{ 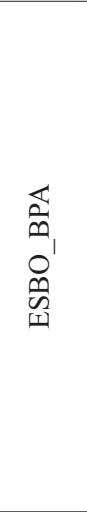 } & 3412 & $-\mathrm{OH}$ & stretching \\
\hline & 2930 & $-\mathrm{CH}_{2}$ & asymmetric stretching \\
\hline & 2853 & $-\mathrm{CH}_{2}$ & symmetric stretching \\
\hline & 1741 & $-\mathrm{C}=\mathrm{O}$ & stretching \\
\hline & 1613 & $-\mathrm{C}=\mathrm{C}-$ & aromatic ring \\
\hline & 1594 & $-\mathrm{C}=\mathrm{C}-$ & aromatic ring \\
\hline & 1464 & $-\mathrm{CH}_{2}$ & scissor deformational \\
\hline & 1381 & $-\mathrm{CH}_{3}$ & symmetric deformational \\
\hline & 1238 & $-\mathrm{C}-\mathrm{O}-\mathrm{C}-$ & epoxy group stretching \\
\hline & 1176 & $-\mathrm{C}-\mathrm{OH}$ & stretching in phenol group \\
\hline & 842 & $-\mathrm{C}-\mathrm{C}-$ & covalent from isopropyl group \\
\hline & 725 & $-\mathrm{CH}_{2}$ & oscillating \\
\hline
\end{tabular}

L1 molecule of triglyceride (section 3). Of course, as a result of parallel reactions presented in Figure 1 there are created much larger macromolecules, having a weight average molecular weight of more than $10000 \mathrm{~g} / \mathrm{mol}$ (Figure 2, section 4). The full characteristic of the epoxy fusion product including the content of functional groups is presented in the Table 2. Based on the FT-IR analysis, obtained product consists both epoxy and hydroxyl groups, which can be used mention here, that the right selection of crosslinking agent and the condition of the crosslinking reaction are crucial for the final mechanical properties of successfully for crosslinking purposes. It is worth to epoxy materials. Polyisocyanates aren't of course typical curing agents used in the technology of epoxy resins, however they were applied here due to the large content of free hydroxyl groups in the epoxy fusion product. The epoxy resins based on modified soybean oil were cured with polyisocyanates of different structure (Figure 3), both aromatic and aliphatic. As it is well known the structure of the isocyanate determinates its reactivity: aromatic isocyanates are more reactive than aliphatic ones, due to the presence of the partial positive charge on the carbon atom and the cumulated system of double bonds [25].

Based on numerous experiments performed using the same epoxy fusion product (ESBO_BPA) and isocyanates with different structure, it was observed that the obtained materials have various mechanical characteristics: from elastomer-like to hard and brittle materials. Crosslinking itself was performed without or with the presence of catalysts, Dabco T9 and Dabco 33-LV (Figure 3). The use of the catalyst was dictated by preventing the reaction of - $\mathrm{NCO}$ groups of isocyanate with air moisture and accelerating the curing process by their reaction with hydroxyl groups of the epoxy fusion product. Moreover, it is worth pointing out that the reaction of moisture from the air with the isocyanate groups, in the case of the novel bio-base epoxy materials synthesis, is potentially unwanted, especially that it may result in gassing and the formation of blisters on the surface of the cured material and degrade its properties. Dabco T9 and Dabco 33-LV were chosen as representative among two groups of catalysts used in polyurethane technology: amine catalysts and organometallics. The drawback of using amine catalyst is their unpleasant fishlike odor and high volatility. For the purpose of our experiment, Dabco 33-LV catalyst was chosen. It is a tertiary amine, which due to its very strong catalytic properties is used in a form of a mixture of $33 \mathrm{wt} \%$ of triethylenediamine and $67 \mathrm{wt} \%$ of dipropylene glycol. Dabco 33-LV has strong influence on promoting

Table 2. Fusion products characteristics

\begin{tabular}{|c|c|c|c|c|c|c|c|c|}
\hline \multirow{2}{*}{$\begin{array}{l}\text { Oil/Epoxy fusion } \\
\text { product }^{\mathrm{a}}\end{array}$} & \multirow{2}{*}{$\begin{array}{c}\bar{M}_{\mathrm{n}} \\
{[\mathrm{g} / \mathrm{mol}]}\end{array}$} & \multirow{2}{*}{$\begin{array}{c}\bar{M}_{\mathrm{w}} \\
{[\mathrm{g} / \mathrm{mol}]}\end{array}$} & \multirow{2}{*}{ PDI $^{d}$} & \multirow{2}{*}{$\begin{array}{c}\mathrm{EV}_{1} \\
{[\mathrm{~mol} / 100 \mathrm{~g}]}\end{array}$} & \multirow{2}{*}{$\begin{array}{c}\mathrm{HV}_{1} \\
{[\mathrm{mgKOH} / \mathrm{g}]}\end{array}$} & \multicolumn{2}{|c|}{ FT_IR absorption bands } & \multirow{2}{*}{$\begin{array}{c}\mu^{\mathrm{e}} \\
{[\mathbf{m P a} \cdot \mathbf{s}]}\end{array}$} \\
\hline & & & & & & Epoxy groups & Hydroxyl groups & \\
\hline $\mathrm{ESBO}^{\mathrm{b}}$ & 968 & 1299 & 1.34 & 0.363 & 5 & 824 & - & $343.7 \pm 1.0$ \\
\hline $\mathrm{ESBO}_{\mathrm{BPA}}{ }^{\mathrm{c}}$ & 1668 & 3981 & 2.39 & 0.118 & 144 & - & $3190-3692$ & $25770.0 \pm 121.0$ \\
\hline
\end{tabular}

${ }^{\mathrm{a}}$ Epoxy fusion product - final product of the reaction of epoxidized soybean oil $\left(\mathrm{ESBO}_{\mathrm{H}_{2} \mathrm{SO}_{4}}, \mathrm{ESBO}_{\mathrm{Zerolit} 325}, \mathrm{ESBO}_{\mathrm{Amberlyst} 15}\right.$,

$\mathrm{ESBO}_{\text {Novozym 435) with bisphenol }}$

${ }^{b}$ Defined before the fusion process

${ }^{\mathrm{c}}$ Defined after the fusion process

dPolydispersity

eViscosity 


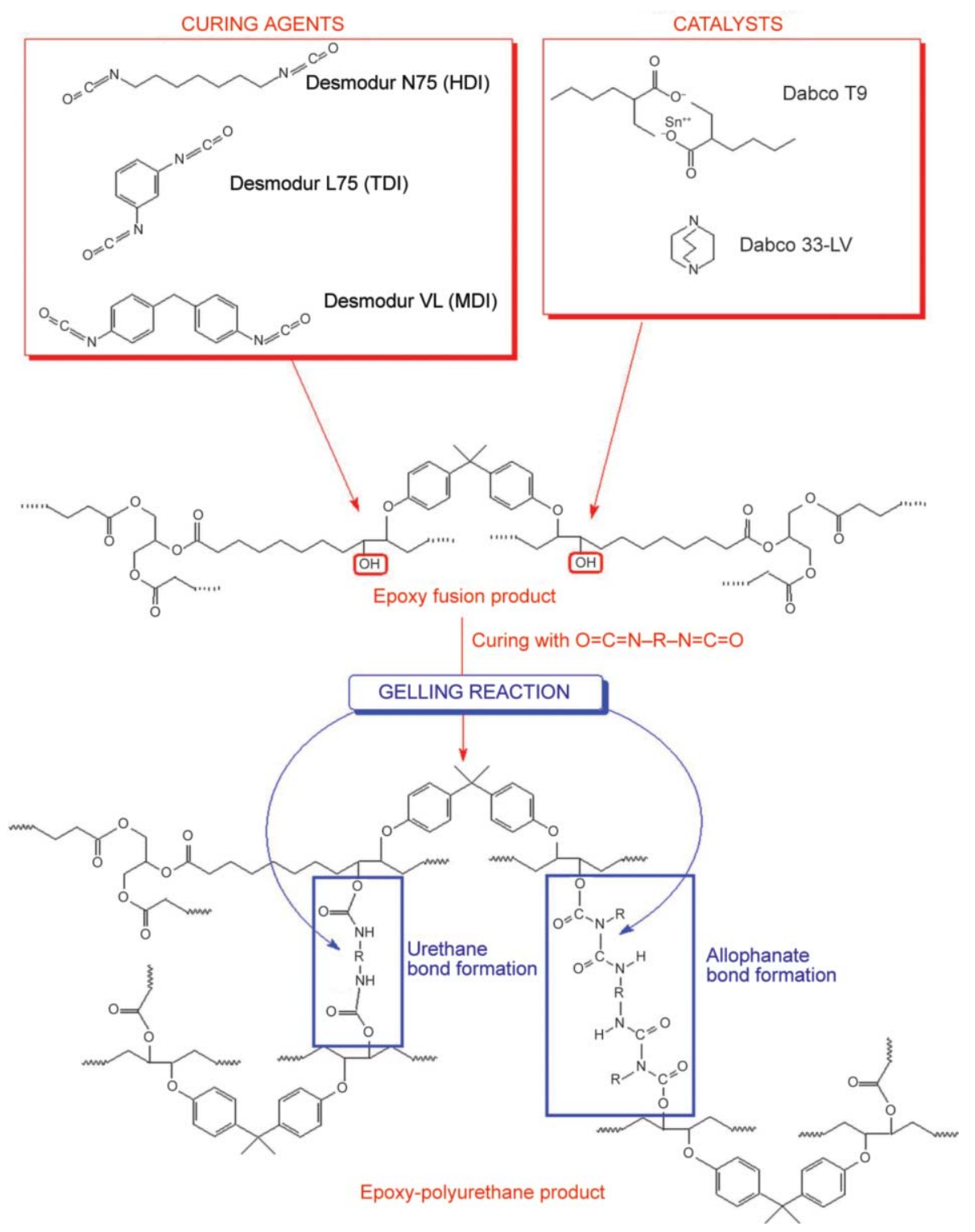

Figure 3. Reagents used in crosslinking process

the urethane (polyol - isocyanate) reaction in a variety of flexible and rigid foam applications. On the other hand, organometallic catalysts are considered as gel catalysts, which, may have some influence on blowing reaction $[26,27]$. For the purpose of our experiment, Dabco T9 was chosen, as a representative of organometallics. It is stannous octoate, and is considered as a strong, metal-based urethane (polyol isocyanate) catalyst that is primarily used in flexible slabstock polyurehane foams. According to the research conducted by Kricheldorf et al. [28] presence of $-\mathrm{OH}$ groups may have significant influence on the early stages of the catalytic performance of stannous octoate catalyst. It had been found that at first hydroxyfunctional impurities (e.g., water) complex and subsequently react with catalyst producing a stannous alkoxide species and free 2-ethylhexanoic acid, then in the second reaction with hydroxyl group the stannous dialkoxide initiator and 2-ethylhexanoic acid are formed. However it is worth to mention that presence of excess water leads to deactivation of catalyst through the reversible reactions to mentioned above. It was also observed that formed urethane groups exhibit catalytic activity in the hydroxyl/isocyanate reaction. Based on performed crosslinking tests, nine compositions were prepared and their mechanical properties were tested. Each composition consists epoxy fusion product ESBO, chosen isocyanate: toluene-2,4-diisocyanate, hexamethylene diisocyanate and 4,4'-methylene diphenyl diisocyanate and $1 \mathrm{wt} \%$ of deaerator BYK A530 (Table 3).

The crosslinking agent was applied in a stoichiometric amount corresponding to the content of the functional groups in epoxy fusion product. The 
Table 3. List of the cured compositions submitted to mechanical properties testing

\begin{tabular}{|c|c|c|c|c|}
\hline Composition & Epoxy fusion product & Isocyanate & Catalyst & Deaerator \\
\hline 1 & \multirow{3}{*}{ ESBO_BPA } & \multirow{3}{*}{ HDI } & - & \multirow{3}{*}{ BYK A530 } \\
\hline 2 & & & Dabco T9 & \\
\hline 3 & & & Dabco 33-LV & \\
\hline 4 & \multirow{3}{*}{ ESBO_BPA } & \multirow{3}{*}{ MDI } & - & \multirow{3}{*}{ BYK A530 } \\
\hline 5 & & & Dabco T9 & \\
\hline 6 & & & Dabco 33-LV & \\
\hline 7 & \multirow{3}{*}{ ESBO_BPA } & \multirow{3}{*}{ TDI } & - & \multirow{3}{*}{ BYK A530 } \\
\hline 8 & & & Dabco T9 & \\
\hline 9 & & & Dabco 33-LV & \\
\hline
\end{tabular}

crosslinking process was performed in open forms in the room temperature for $24 \mathrm{~h}$, allowing undisturbed reaction of functional groups to take place. Afterwards, curing of prepared material was continued in the temperature of $80^{\circ} \mathrm{C}$ for another $24 \mathrm{~h}$ (full conversion of functional groups and reduction of the necessary time, which is usually applied for all samples before testing their mechanical properties). During both the preparation and the casting of the epoxy-polyurethane material, no significant differences were observed. After $24 \mathrm{~h}$, cured compositions were easy to remove from forms, however compositions: 1 (ESBO_BPA + HDI) and 3 (ESBO_BPA + HDI + D_33-LV) were relatively elastic and nontransparent, while 2, 4-9 remained rigid. Additionally 2 (ESBO_BPA + HDI + D_T9) had clearly marked two layers: external - slightly foamy and internal - non-foamy and transparent.

The structure of cured samples was analyzed using the FT-IR spectra (Figure 4), which confirmed that the crosslinking process with the utilization of hydroxyl groups took place. The decrease of the intensity from -OH groups $\left(v=3412 \mathrm{~cm}^{-1}\right)$ as well appearance of new bands from urethane groups are observed (1735-1700 $\left.\mathrm{cm}^{-1}\right)$.

The analysis of SEM microphotographs of the impact fracture surface of crosslinked epoxy-polyurethane material based on epoxy fusion product of epoxidized soybean oil and bisphenol A (Figure 5) shows that the structure of obtained polymer material is homogeneous and there is no visible phase separation which is common for the polymer materials based on epoxy resin and epoxidized vegetable oil [17]. In such materials, microdomains of modified oil or low molecular weight oligomers are typically observed. According to the results of GPC analysis the epoxy fusion product does not contain unreacted epoxidized soybean oil, however there are vestiges of unreacted bisphenol A. Such unreacted

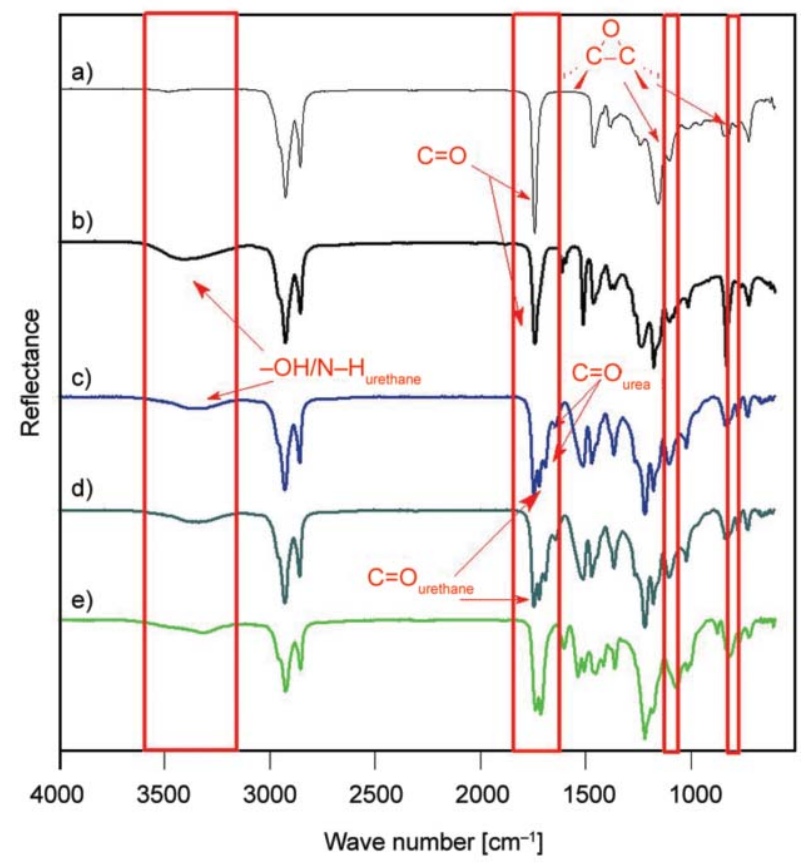

Figure 4. FT-IR ATR spectra of the epoxidized soybean oil (a), epoxy fusion product of epoxidized soybean oil and bisphenol A (b), and crosslinked with HDI (c), MDI (d) or TDI (e) epoxy-polyurethane materials

residues of unconverted bisphenol A are always observed in case of the synthesis of epoxy resins [14]. It does not contribute any problems, since bisphenol A contains hydroxyl groups and in curing process it reacts with the isocyanate (determination of $-\mathrm{OH}$ groups content in the reacting mixture). However, due to the (i) different polarity of the epoxy fusion product and unreacted bisphenol A, as well as (ii) different reactivity of secondary hydroxyl and phenol groups, the separation of phases could potentially be observed. In a case of prepared epoxy-polyurethane samples, the SEM analysis has provided very important information - discussed above phase separation is not observed. Additionally, based on SEM analysis, it is worth pointing out that epoxy-polyurethane compositions based on modified soybean oil did not 


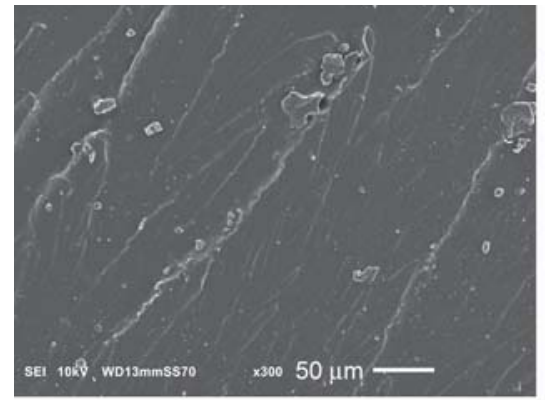

a)

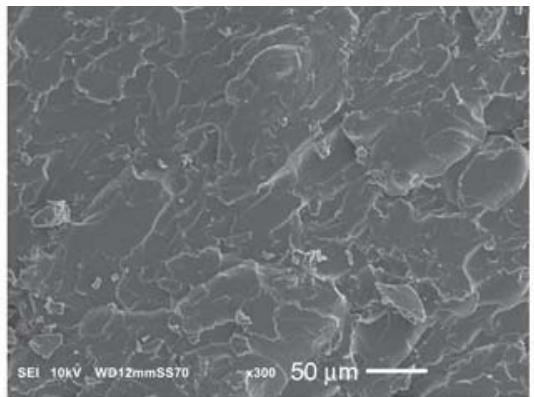

b)

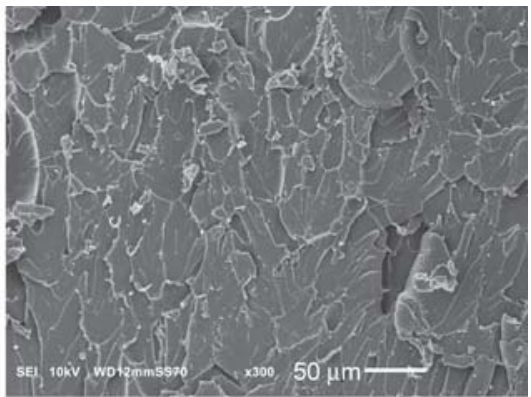

c)

Figure 5. SEM microphotographs of the impact fracture surface of crosslinked epoxy-polyurethane material based on epoxy fusion product of epoxidized soybean oil and bisphenol A, a) ESBO_BPA + HDI + D_T9, b) ESBO_BPA + MDI + D_T9, c) ESBO_BPA + TDI + D_T9

show brittle fractures, which are typical for the conventional epoxy resins.

Additionally, using TGA and DTG method, the thermal stability of the obtained epoxy-polyurethane materials for representative samples of different curing agents had been also analyzed (Figure 6, Table 4). For the composition: ESBO_BPA + HDI + Dabco T9 the weight loss starts at about $58^{\circ} \mathrm{C}$ and it is observed to approx. $230^{\circ} \mathrm{C}$. The weight loss of approx. $2 \mathrm{wt} \%$ is associated with the evaporation of water and optionally unreacted isocyanate. The course of thermal degradation of this composition is a twostep. At the temperature of $271^{\circ} \mathrm{C}$ the first step of decomposition begins. Up to the temperature of approx. $360-370^{\circ} \mathrm{C}$ cracking of uretane bonds is taking place. The second stage of the decomposition, occurring above $380^{\circ} \mathrm{C}$, is associated with the degradation of ether linkages between triglycerid molecule and bisphenol A. Above $460^{\circ} \mathrm{C}$ starts the decomposition

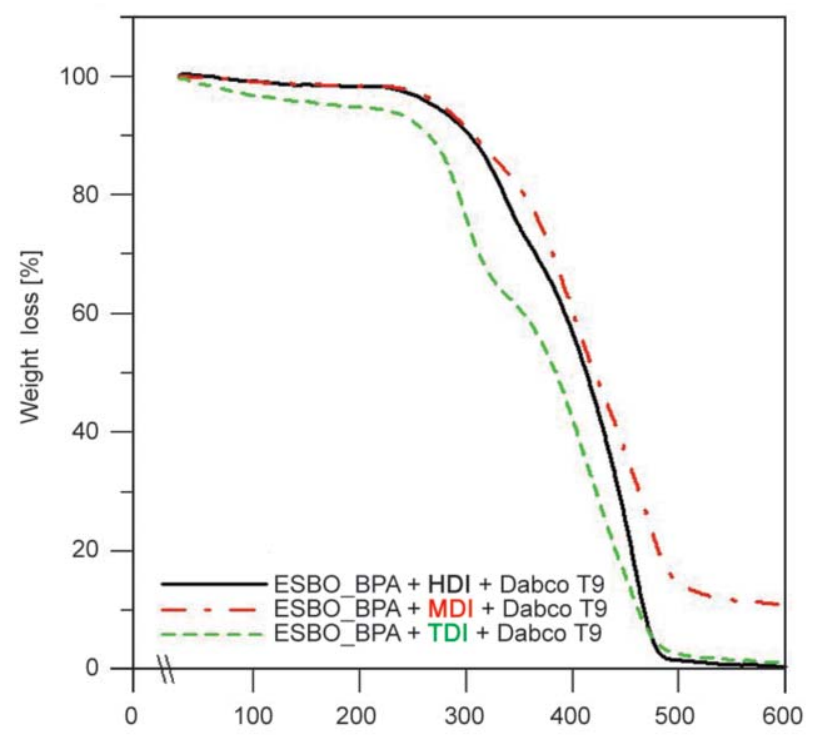

a)

Temperature $\left[{ }^{\circ} \mathrm{C}\right]$ of fatty acid chains of triglycerides. The degradation of bisphenol A particles, which were embedded in the epoxy fusion process is taking place above $400^{\circ} \mathrm{C}$. Simmilar to described composition, the weight loss of ESBO_BPA + MDI + Dabco T9 begins at about $60^{\circ} \mathrm{C}$ and it is observed up to the temperature approx. $232{ }^{\circ} \mathrm{C}$. This weight loss, also by approx. $2 \mathrm{wt} \%$, as in the case of compositions cured with HDI, is related to the evaporation of the water and the unreacted isocyanate. Material cured with MDI is characterized by a corresponding two-stage course of thermal degradation. The only difference is that above the temperature of $350^{\circ} \mathrm{C}$ degradation of MDI is observed. Increased residue weight after degradation may be associated with a slower decomposition of aromatic structures of MDI. In the case of TDI cured composition (ESBO_BPA + MDI + Dabco T9) somewhat different course of degradation is observed than for the epoxy fusion product crosslinked

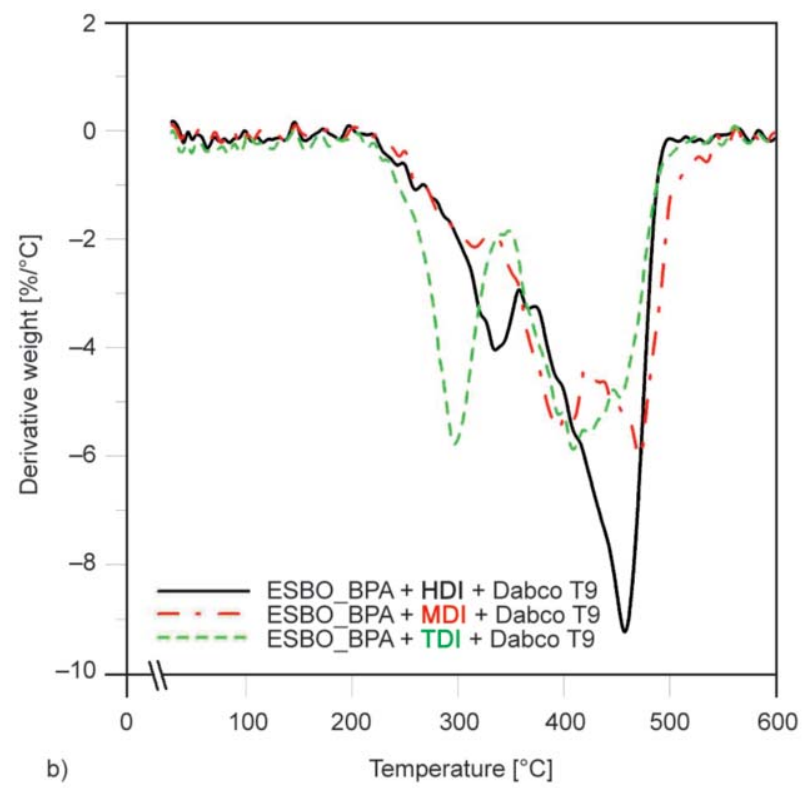

Figure 6. TGA and DTG analysis of crosslinked epoxy-polyurethane compositions, a) TGA, b) DTG 
Table 4. Initial decomposition temperatures (IDT) and char residues for the cured products of the epoxy fusion process

\begin{tabular}{|c|c|c|c|c|c|c|}
\hline Composition & $\begin{array}{l}\text { IDT }_{1} \\
{\left[{ }^{\circ} \mathrm{C}\right]}\end{array}$ & $\begin{array}{l}\text { IDT }_{2} \\
{\left[{ }^{\circ} \mathrm{C}\right]}\end{array}$ & $\begin{array}{l}T_{10 \%} \\
{\left[{ }^{\circ} \mathrm{C}\right]}\end{array}$ & $\begin{array}{l}T_{20 \%} \\
{\left[{ }^{\circ} \mathbf{C}\right]}\end{array}$ & $\begin{array}{l}T_{50 \%} \\
{\left[{ }^{\circ} \mathrm{C}\right]}\end{array}$ & $\begin{array}{c}\text { Char residue } \\
{[\%]}\end{array}$ \\
\hline ESBO_BPA + HDI + Dabco T9 & 272.2 & 383.0 & 303.6 & 336.0 & 413.2 & 0.4 \\
\hline ESBO_BPA + MDI + Dabco T9 & 275.4 & 370.8 & 307.6 & 354.8 & 421.8 & 10.9 \\
\hline ESBO_BPA + TDI + Dabco T9 & 269.3 & 371.0 & 265.3 & 293.5 & 384.4 & 1.0 \\
\hline
\end{tabular}

Table 5. Mechanical properties of crosslinked epoxy-polyurethane material based on epoxy fusion product of epoxidized soybean oil and bisphenol A

\begin{tabular}{|c|c|c|c|c|c|c|c|c|c|}
\hline \multirow{2}{*}{$\begin{array}{l}\text { Mechanical } \\
\text { properties }\end{array}$} & \multicolumn{9}{|c|}{ Tested composition } \\
\hline & 1 & 2 & 3 & 4 & 5 & 6 & 7 & 8 & 9 \\
\hline $\begin{array}{l}\text { Tensile strength } \\
{[\mathrm{MPa}]}\end{array}$ & $1.17 \pm 0.04$ & $2.91 \pm 0.19$ & $0.72 \pm 0.16$ & $10.96 \pm 0.69$ & $8.00 \pm 0.59$ & $8.84 \pm 1.78$ & $12.06 \pm 0.35$ & $13.95 \pm 0.45$ & $12.65 \pm 1.74$ \\
\hline $\begin{array}{l}\text { Elongation at } \\
\text { break [\%] }\end{array}$ & $17.9 \pm 2.0$ & $27.0 \pm 1.3$ & $17.4 \pm 2.4$ & $6.5 \pm 2.2$ & $7.2 \pm 2.4$ & $5.9 \pm 3.3$ & $3.9 \pm 0.9$ & $8.4 \pm 4.8$ & $3.2 \pm 1.4$ \\
\hline $\begin{array}{l}\text { Modulus of } \\
\text { elasticity [MPa] }\end{array}$ & $6.8 \pm 0.8$ & $27.5 \pm 1.3$ & $5.5 \pm 0.8$ & $426.9 \pm 56.1$ & $290.2 \pm 24.5$ & $350.4 \pm 60.4$ & $464.5 \pm 10.7$ & $496.8 \pm 56.4$ & $572.6 \pm 44.9$ \\
\hline $\begin{array}{l}\text { Flexural strength } \\
{[\mathrm{MPa}]}\end{array}$ & - & $1.39 \pm 0.86$ & - & $8.13 \pm 1.11$ & $8.31 \pm 0.91$ & $11.94 \pm 1.15$ & $16.27 \pm 1.37$ & $19.42 \pm 1.53$ & $19.39 \pm 1.63$ \\
\hline $\begin{array}{l}\text { Elasticity } \\
\text { flexural modulus } \\
{[\mathrm{MPa}]}\end{array}$ & - & $21.4 \pm 0.6$ & - & $70.2 \pm 44.0$ & $111.1 \pm 40.0$ & $183.9 \pm 54.0$ & $341.0 \pm 58.0$ & $482.0 \pm 93.0$ & $401.0 \pm 94.5$ \\
\hline Deflection [\%] & - & $7.2 \pm 0.6$ & - & $9.12 \pm 1.70$ & $7.5 \pm 0.9$ & $6.8 \pm 0.7$ & $6.1 \pm 0.2$ & $6.0 \pm 0.2$ & $6.1 \pm 0.1$ \\
\hline $\begin{array}{l}\text { Compressive } \\
\text { strength [MPa] }\end{array}$ & $0.55 \pm 0.07$ & $1.55 \pm 0.13$ & $0.73 \pm 0.09$ & $7.60 \pm 1.50$ & $8.20 \pm 1.0$ & $8.60 \pm 2.30$ & $8.30 \pm 1.9$ & $8.70 \pm 0.90$ & $5.10 \pm 2.40$ \\
\hline $\begin{array}{l}\text { Compression set } \\
{[\%]}\end{array}$ & $2.8 \pm 0.0$ & $2.8 \pm 0.0$ & $2.8 \pm 0.0$ & $1.4 \pm 0.0$ & $1.8 \pm 0.3$ & $2.0 \pm 0.0$ & $1.9 \pm 0.1$ & $2.0 \pm 0.0$ & $1.9 \pm 0.1$ \\
\hline $\begin{array}{l}\text { Shore Hardness } \\
{\left[\mathrm{Sh}^{\circ} \mathrm{A}\right]}\end{array}$ & $63.0 \pm 2.2$ & $73.6 \pm 2.2$ & $50.5 \pm 4.5$ & $97.0 \pm 0.3$ & $96.9 \pm 1.2$ & $91.8 \pm 1.4$ & $94.8 \pm 1.1$ & $94.4 \pm 1.9$ & $96.8 \pm 0.6$ \\
\hline $\begin{array}{l}\text { Impact } \\
\text { toughness }\left[\mathrm{kJ} / \mathrm{m}^{2}\right]\end{array}$ & - & - & - & $9.4 \pm 0.8$ & $5.9 \pm 1.3$ & $7.5 \pm 1.3$ & $7.5 \pm 0.7$ & $4.6 \pm 0.2$ & $3.7 \pm 0.0$ \\
\hline Resilience $[\mathrm{cm}]$ & $6.0 \pm 0.9$ & $12.0 \pm 0.8$ & $3.0 \pm 0.5$ & $20.7 \pm 1.1$ & $22.1 \pm 0.4$ & $21.6 \pm 0.5$ & $25.0 \pm 0.6$ & $23.7 \pm 0.5$ & $25.0 \pm 0.6$ \\
\hline
\end{tabular}

with HDI and MDI. The initial weight loss starts a little earlier, because already at approx. $41{ }^{\circ} \mathrm{C}$. Despite that fact, this stage ends in the same way as in the case of already described compositions, in the vicinity of the temperature of $226^{\circ} \mathrm{C}$, but at this range its weight loss is about of $5.8 \mathrm{wt} \%$. This may be due to a reduced degree of cross-linking of this composition ocurred as a result of incomplete reaction of the isocyanate. Confirmation of such assumption may be the fact that the first and second stage of degradation starts at a slightly lower temperature than in the case of compositions cured with HDI and MDI.

In the next step of conducted experiment mechanical properties have been determined (Table 5).

The results of mechanical tests confirmed our predictions: properties of crosslinked materials depend on the type of chosen isocyanate used as a curing agent. It was found that, in a case of aliphatic isocyanate, obtained material is characterized by small mechanical resistance. On the other hand compositions cured with MDI and TDI are rigid with high mechanical resistance. It was observed that compo- sitions prepared with the use of TDI are characterized by the highest value of tensile strength with the smallest value of elongation at break. For aromatic diisocyanates, MDI and TDI, the difference in the structure has an influence onto the mechanical properties of polymer material crosslinked with their use. MDI is linear and symmetric, having two aromatic rings, resulting in relatively close co-existence of urethane and ester groups, and potential chance of intermolecular plasticization, leading to worse mechanical properties in comparison to material cured with TDI. On the other hand polymer material based on HDI is characterized by high elasticity, two times higher tensile strength and modulus of elasticity than polyurethane elastomer based on polyol from soybean oil and HDI, described in the literature [29]. At the same time it presents comparable hardness in the Shore's A scale (67.4-87.7 $\mathrm{Sh}^{\circ} \mathrm{A}$ ) [30-32] to polyurethane elastomers based on different vegetable oils. Moreover, the analysis of mechanical tests indicate that, application of aromatic isocyanate, toluene-2,4diisocyanate, results in obtaining the composition 
with relatively high values of tensile strength and modulus of elasticity, however the smallest values of elongation at break. Aliphatic isocyanates give a material with the highest values of elongation at break and smallest values of tensile strength. Additionally, compositions based on TDI present the highest modulus of elasticity flexural modulus. Materials based on HDI turned out to be very elastic, resulting in impossibility of flexural strength determination.

Comparison of modulus of elasticity and elasticity flexural modulus maintain in the same relation as mentioned above - the highest modulus is observed for compositions based on TDI (572.6 and $482.0 \mathrm{MPa}$, respectively), followed by epoxy-polyurethane materials with MDI (429.9 and $183.8 \mathrm{MPa}$, respectively) and the lowest values were achieved for HDI samples (27.5 and 21.4 MPa, respectively). Only one exception is observed within the TDI group of materials, where the highest value of modulus of elasticity was obtained for composition crosslinked in the presence of catalyst Dabco 33-LV (572.6 MPa TDI/Dabco 33-LV and 496.8 MPa - TDI/Dabco T9). Since synthesized compositions exhibit mechanical properties comparable to elastomer-like materials (e.g., polyurethane elastomers), higher values of static mechanical modulus may be correlated with the increase of the degree of arrangement of the material structure. Additionally, when the molecular chains are closely packed and parallel, the secondary bonding is enhanced resulting in increase of mechanical strength. It was also observed that application of the catalyst has substantial influence on the course of crosslinking process, which at the same time determines postcuring mechanical parameters of the prepared composition. Wherein the application of organometallic catalyst Dabco T9 in case of compositions based on TDI contribute to a substantial increase of elongation at break value, with simultaneous practically unchanged value of modulus of elasticity and worsen of compressive strength compared to composition without catalyst. Additionally, interesting properties presents composition $\mathbf{2}$, cured with HDI in a presence of organometallic catalyst Dabco T9, which is characterized by higher tensile and compressive strength, with additionally almost triple increase of modulus of elasticity in comparison to the composition cured without the presence of catalyst. At the same time composition $\mathbf{2}$ is characterized by the highest elongation at break among all obtained materials.
Materials cured with toluene-2,4-diisocyanate and 4,4'-methylene diphenyl diisocyanate are characterized by the highest value of hardness in a Shore's A scale with simultaneous the highest resilience value. Material cured with 4,4'-methylene diphenyl diisocyanate presents the highest value of deflection.

\section{Conclusions}

The application of the epoxy fusion process, where the reaction is conducted in bulk, allows obtaining the final product without the necessity of removing e.g. the solvent. On the other hand, the application of vegetable oil gives the material with lower rigidity and higher elasticity than typical products of epoxy fusion process. Additionally, those interesting properties depending on applied vegetable oil may be modified by the proper selection of the hardener and the catalyst of crosslinking. Both epoxy and hydroxyl groups present in the structure of the epoxy fusion product can be used for crosslinking purposes. Cured with polyisocyanates bio-resins are characterized by differential mechanical properties, which depend on the type of chosen isocyanate. Aromatic TDI gives the material with relatively high values of tensile strength and modulus of elasticity, however the smallest elongation at break. Aliphatic diisocyanate gives material with the highest values of elongation at break and the smallest tensile strength. Mechanical resistance of hybrid epoxy-polyurethane materials cured with MDI and TDI is higher than the one of Ruetapox 162 cured with methyltetrahydrophthalic anhydride, however lower while cured with isophoronediamine.

\section{References}

[1] Roşu D., Caşcaval C. N., Mustaţă F., Ciobanu C.: Cure kinetics of epoxy resins studied by non-isothermal DSC data. Thermochimica Acta, 383, 119-127 (2002). https://doi.org/10.1016/S0040-6031(01)00672-4

[2] Fombuena V., Bernardi L., Fenollar O., Boronat T., Balart R.: Characterization of green composites from biobased epoxy matrices and bio-fillers derived from seashell wastes. Materials and Design, 57, 168-174 (2014). https://doi.org/10.1016/j.matdes.2013.12.032

[3] Petrie E. M.: Epoxy adhesive formulations. McGrawHill Publishing, New York (2006).

[4] Pham H. Q., Marks M. J.: Encyclopaedia of polymer science and technology. Wiley, New York (2004).

[5] Sinh L. H., Trung N. N., Son B. T., Shin S., Thanh D. T., Bae J-Y.: Curing behavior, thermal, and mechanical properties of epoxy resins cured with a novel liquid crystalline dicarboxylic acid curing agent. Polymer Engineering and Science, 54, 695-703 (2014). https://doi.org/10.1002/pen.23585 
[6] Wang H., Zhang Y., Zhu L., Du Z., Zhang B., Zhang Y.: Curing behaviors and kinetics of epoxy resins with a series of biphenyl curing agents having different methylene units. Thermochimica Acta, 521, 18-25 (2011). https://doi.org/10.1016/j.tca.2011.03.036

[7] Czub P., Bończa-Tomaszewski Z., Penczek P., Pielichowski J.: Chemistry and technology of epoxy resins. WNT, Warsaw (2002).

[8] Meier M. A. R., Metzger J. O., Schubert U. S.: Plant oil renewable resources as green alternatives in polymer science. Chemical Society Reviews, 36, 1788-1802 (2007). https://doi.org/10.1039/b703294c

[9] Mapleston P.: New technologies for a greener industry. Plastics Engineering, 64, 10-15 (2008).

[10] Keleş E., Hazer B.: Synthesis of segmented polyurethane based on polymeric soybean oil polyol and poly (ethylene glycol). Journal of Polymers and the Environment, 17, 153-158 (2009).

https://doi.org/10.1007/s10924-009-0132-0

[11] Hazer B., Akyol E.: Efficiency of gold nano particles on the autoxidized soybean oil polymer: Fractionation and structural analysis. Journal of the American Oil Chemists' Society, 93, 201-213 (2016). https://doi.org/10.1007/s11746-015-2764-7

[12] Sharmin E., Zafar F., Akram D., Alam M., Ahmad S.: Recent advances in vegetable oils based environment friendly coatings: A review. Industrial Crops and Products, 76, 215-229 (2015).

https://doi.org/10.1016/j.indcrop.2015.06.022

[13] Czub P.: Application of modified natural oils as reactive diluents for epoxy resins. Macromolecular Symposia, 242, 60-64 (2006). https://doi.org/10.1002/masy.200651010

[14] Stemmelen M., Lapinte V., Habas J-P., Robin J-J.: Plant oil-based epoxy resins from fatty diamines and epoxidized vegetable oil. European Polymer Journal, 68, 536-545 (2015).

https://doi.org/10.1016/j.eurpolymj.2015.03.062

[15] Mazzon E., Habas-Ulloa A., Habas J-P.: Lightweight rigid foams from highly reactive epoxy resins derived from vegetable oil for automotive applications. European Polymer Journal, 68, 546-557 (2015). https://doi.org/10.1016/j.eurpolymj.2015.03.064

[16] Górczyk J., Bogdał D., Pielichowski J., Penczek P.: Epoxy resins with enhanced molecular weight - Synthesis and thermal characteristics. Polimery, 51, 781790 (2006).

[17] Czub P.: Characterization of an epoxy resin modified with natural oil-based reactive diluents. Macromolecular Symposia, 245-246, 533-538 (2006).

https://doi.org/10.1002/masy.200651377

[18] Czub P., Kasza P.: Study on mechanical properties of the crosslinked with isocyanates product of the reaction of modified soybean oil with epoxy resin. Polimery, 59, 466-476 (2014).

https://doi.org/10.14314/polimery.2014.466
[19] Arimitsu K., Fuse S., Kudo K., Furutani M.: Imidazole derivatives as latent curing agents for epoxy thermosetting resins. Materials Letters, 161, 408-410 (2015). https://doi.org/10.1016/j.matlet.2015.08.141

[20] Ji D., Fang Z., He W., Luo Z., Jiang X., Wang T., Guo K.: Polyurethane rigid foams formed from different soy-based polyols by the ring opening of epoxidised soybean oil with methanol, phenol, and cyclohexanol. Industrial Crops and Products, 74, 76-82 (2015). https://doi.org/10.1016/j.indcrop.2015.04.041

[21] Li Y., Sun X. S.: Polyols from epoxidized soybean oil and alpha hydroxyl acids and their adhesion properties from UV polymerization. International Journal of Adhesion and Adhesives, 63, 1-8 (2015). https://doi.org/10.1016/j.ijadhadh.2015.07.013

[22] Czub P.: Synthesis of high-molecular-weight epoxy resins from modified natural oils and Bisphenol A or Bisphenol A-based epoxy resins. Polymers for Advanced Technolologyes, 20, 194-208 (2009). https://doi.org/10.1002/pat.1252

[23] Czub P.: A comparison of the syntheses of high molar mass epoxy resins on the basis of two groups of modified vegetable oils. Macromolecular Symposia, 277, 162-170 (2009).

https://doi.org/10.1002/masy.200950320

[24] Jackson R. J.: Epoxy fusion catalyst and process. U.S. Patent 4829141, USA (1989).

[25] Prociak A., Rokicki G., Ryszkowska J.: Polyurethane materials. PWN, Warsaw (2014).

[26] Randall D., Lee S.: The polyurethanes book. Wiley, Chichester (2002).

[27] Woods G.: Flexible polyurethane foams. Applied Science Publishers, London (1982).

[28] Kricheldorf H. R., Kreiser-Saunders I., Stricker A.: Polylactones 48. SnOct ${ }_{2}$-initiated polymerizations of lactide: A mechanistic study. Macromolecules, 33, 702709 (2000).

https://doi.org/10.1021/ma991181w

[29] Narine S. S., Kong X., Bouzidi L., Sporns P.: Physical properties of polyurethanes produced from polyols from seed oils: I. Elastomers. Journal of the American Oil Chemists' Society, 84, 55-63 (2007). https://doi.org/10.1007/s11746-006-1006-4

[30] Prisacariu C.: Polyurethane elastomers: From morphology to mechanical aspects. Springer, New York (2011). https://doi.org/10.1007/978-3-7091-0514-6

[31] Rohaeti E., Kristianingrum S., Partana C. F.: Synthesis of polyurethane elastomer from vegetable oil and methylene-4, 4'-diphenyldiisocyanate (MDI) as surface coating for roller. in 'Proceeding of International Conference on Mathematics and Natural Sciences (ICMNS), Bandung, Indonesia' 639-642 (2006).

[32] Wang C-S., Yang L-T., Ni B-L., Shi G.: Polyurethane networks from different soy-based polyols by the ring opening of epoxidized soybean oil with methanol, glycol, and 1,2-propanediol. Journal of Applied Polymer Science, 114, 125-131 (2009). https://doi.org/10.1002/app.30493 